\title{
Indicators of readiness and capacity for implementation of healthy food retail interventions
}

\author{
Jennifer Sanchez-Flack a* \\ University of Illinois at Chicago
}

Kakul Joshi, b Eunice E. Lee, ${ }^{\mathrm{c}}$ and Darcy A. Freedman d

Case Western Reserve University

Submitted October 22, 2020 / Revised December 16, 2020, and January 5, 2021 / Accepted January 6, 2021 /

Published online May 17, 2021

Citation: Sanchez-Flack, J., Joshi, K., Lee, E. E., \& Freedman, D A. (2021). Indicators of readiness and capacity for implementation of healthy food retail interventions. Journal of Agriculture, Food Systems, and Community Development, 10(3), 127-143. https://doi.org/10.5304/jafscd.2021.103.007

Copyright (C) 2021 by the Authors. Published by the Lyson Center for Civic Agriculture and Food Systems. Open access under CC-BY license.

\begin{abstract}
Healthy food retail (HFR) interventions are a recommended strategy to improve the dietary behaviors of low-income residents with limited
\end{abstract}

a * Corresponding author: Jennifer Sanchez-Flack, MPH, PhD, Visiting Research Assistant Professor, Department of Pediatrics, University of Illinois Cancer Center, and the Institute for Health Research and Policy, University of Illinois at Chicago; 1747 West Roosevelt Road, WROB 478; Chicago, IL60608 USA; jsanch38@uic.edu

${ }^{\mathrm{b}}$ Kakul Joshi, MPH, PhD Candidate, Department of Population and Quantitative Health Sciences at School of Medicine, Case Western Reserve University; 10900 Euclid Avenue; Cleveland, OH 44106 USA; kxj106@case.edu

${ }^{c}$ Eunice E. Lee, PhD, MSW, National Research Service Award Fellow, Department of Bioethics, School of Medicine, Case Western Reserve University; 10900 Euclid Avenue; Cleveland, OH 44106 USA; ex1182@,case.edu

d Darcy A. Freedman, MPH, PhD, Director, Mary Ann Swetland Center for Environmental Health, Case Western Reserve University; 10900 Euclid Avenue; Cleveland, OH 44106 USA; daf96@,case.edu access to healthy food; however, tools are needed to assess, tailor, and implement HFR plans to local contexts. The present study identifies factors influencing HFR implementation and presents findings related to identifying, operationalizing, and prioritizing facilitators of and barriers to implementing HFR interventions within low-resource rural and urban contexts. Practitioners and community residents, recruited from nine counties in Ohio, participated in semistructured interviews and focus groups. Grounded theory methodology was used

\section{Funding Disclosure}

This study was funded by the NCI Training Program: Cancer Education \& Career Development Program (T32CA057699) and by the Centers for Disease Control and Prevention, Preventive Health and Health Services Block Grant, award no. 2B01OT009042-15, and by the U.S. Department of Agriculture Nutrition Education and Obesity Grant Program, award number G-1415-17-0847 and award number G-16170452, and the Centers for Disease Control and Prevention Health Promotion and Disease Prevention Research Center supported by Cooperative Agreement Number 1U48DP005030. 
to develop themes and indicators of readiness and capacity for successful HFR implementation. Consensus conference feedback from an expert panel prioritized themes and indicators based on their perceived relevance and importance for successfully implementing HFR interventions. Five themes were identified as influential factors: (1) corner store awareness and perception, (2) organizational and practitioner capacity, (3) community attitudes and perceptions, (4) logistical factors, and (5) networks and relationships. Additionally, 18 indicators within the five themes were identified to further illustrate influential factors to HFR implementation. The themes and indicators presented in this research have been synthesized into the PSE READI tool ${ }^{1}$ (developed outside of this research). The PSE READI tool uniquely provides an opportunity to assess, tailor, and implement HFR plans to the local contexts by considering the key themes and influential factors that emerged from this community-level, qualitative research.

\section{Keywords}

Healthy Food Retail; Dietary Behavior; Policy, System, and Environmental Interventions; Program Implementation

\section{Introduction}

The influence of the food environment on dietary behaviors and health outcomes has been of keen interest to academia and the public health community (Centers for Disease Prevention and Control, 2011; Larson et al., 2009; Treuhaft \& Karpyn, 2015). Retail food outlets such as supermarkets and convenience stores make up a large part of the community food environment (Glanz et al., 2005), and studies have shown that these outlets may contribute to obesity (T. A. Farley et al., 2009; Morland et al., 2006). Living in an area with many convenience stores, which tend to carry a larger proportion of energy-dense foods compared to healthy foods (T. A. Farley et al., 2009), versus an area with multiple supermarkets may influence obesity risk (Morland et al., 2006). Research demonstrates that one's proximity to retail food outlets with high availability of healthy foods is associated with better dietary habits and a decreased risk for diet-related chronic diseases, including obesity (Glanz \& Yaroch, 2004; Story et al., 2008; Treuhaft \& Karpyn, 2015).

Policy, system, and environmental (PSE) interventions encompass multilevel approaches to alter environments such as community and consumer food environments (Frieden, 2010). Community and consumer nutrition interventions to improve these environments are often referred to as healthy food retail (HFR) interventions. These interventions are gaining momentum as a means to create healthier food environments, especially for people living in underserved areas designated as so-called 'food deserts' (Adam \& Jensen, 2016; Gittelsohn et al., 2012; Walker et al., 2010a). The design and implementation of HFR interventions vary based on store type and size, geographic location, and access to community resources needed to support change (Centers for Disease Prevention and Control, 2011; Glanz \& Yaroch, 2004). The popularity of implementation of HFR interventions has increased over recent years in various geographic areas (Pinard et al., 2016), and in multiple types of retail food outlets, including tiendas (Ayala et al., 2013), bodegas (Dannefer et al., 2012), green carts (S. M. Farley et al., 2015), corner stores (Gittelsohn et al., 2012; Langellier et al., 2013), convenience stores, including gas-marts, pharmacies, and dollar stores (Gittelsohn et al., 2012), and supermarkets (Adam \& Jensen, 2016; Hartmann-Boyce et al., 2018). These interventions are more likely to be implemented in urban areas compared to rural areas (Gittelsohn et al., 2012). Examples of the types of HFR interventions that have been implemented previously include increasing the number of healthy food options in corner stores, placement strategies (e.g., placing healthy food items near cash registers), and marketing and promoting healthy food items (e.g., pricing strategies, healthy food advertisements), among others (Adam \& Jensen, 2016; Dannefer et al., 2012; Gittelsohn et al., 2012; Hartmann-Boyce et al., 2018).

Given the range of locations for HFR interventions and differences in these programs' size

${ }^{1}$ The PSE READI website is https://PSEREADI.org 
and scope, there is an opportunity to streamline technical assistance around program implementation to suit one's local context. Toolkits have been created to assist practitioners in developing, implementing, and disseminating multifaceted HFR interventions; however, none of them explicitly address how to tailor implementation within diverse community settings (Building Capacity for Obesity Prevention, 2016). Tools to systematically assess community readiness and capacity to tailor HFR interventions to local contexts' realities help practitioners effectively implement HFR interventions within and across diverse community settings.

The goal of this research was to identify factors perceived to influence the implementation of HFR interventions. This study presents findings related to identifying, operationalizing, and prioritizing facilitators of and barriers to implementing HFR interventions within low-resource rural and urban contexts. Interview and focus group data were collected from two groups: (1) frontline practitioners working with the Ohio Supplemental Nutrition Assistance Program Education (SNAPEd) or the Ohio Department of Health's Creating Healthy Communities (CHC) and (2) community members, to identify factors perceived to influence the implementation of healthy eating PSEs in retail food outlets. We believe our study is the first of its kind in that it not only contributes to the existing literature by identifying facilitators of and barriers to implementation of HFR interventions from the perspectives of experienced stakeholders but also extends research by operationalizing them into measurable indicators resulting in the creation of PSE READI (Readiness Assessment and Decision Instrument tool) (Building Capacity for Obesity Prevention, 2016).

\section{Applied Research Methods}

This study is derived from the Building Capacity for Obesity Prevention (BCOP) project, a university-community partnership aimed at developing web-based community readiness and capacity assessment tools to optimize implementation of four nutrition-related PSE interventions ([1] farmers markets, [2] healthy eating in childcare settings, [3] HFR, and [4] farm to school) (Lee et al., 2017, 2019; Parsons et al., 2019). Details about the overall study methods were previously published (Lee et al., 2017). Figure 1 displays the fivephase consensus modeling process to develop the PSE READI tool for implementing HFR projects. Briefly, Phase I consisted of data collection (interviews with SNAP-Ed and CHC practitioners and focus groups with SNAP-eligible community members and $\mathrm{CHC}$ coalition members) and thematic analysis of transcripts. Phase 2 consisted of indicator development, where an iterative process of discussion and refinement to operationalize indicators among the research team took place. Phase III consisted of a consensus conference where an expert panel reviewed indicators. Phase IV consisted of indicator refinement where similar indicators and themes were refined and merged by the research team. Lastly, Phase V consisted of developing the PSE READI tool for pilot testing with external expert panelists who might be potential end-users of this tool. Community partners included representatives from countywide coalitions supported through the Ohio Department of Health's Creating Healthy Communities (CHC) program. Coalition membership varied by county but included a range of local stakeholders involved with healthy eating and active living initiatives, such as health care and public health practitioners, cooperative extension agents, grassroots and faith-based leaders, educators, and stakeholders from government, nonprofit, and business sectors.

\section{Sampling and Recruitment}

Before data collection, we selected targeted geographic areas to recruit diverse study participants. Specifically, nine counties in Ohio were purposively selected given their representativeness in terms of county health rankings, geographic location, adult obesity rates, and SNAP participation. Additionally, they had on-the-ground SNAP-Ed and CHC staff to support HFR project implementation. Inclusion of on-the-ground SNAP-Ed and $\mathrm{CHC}$ staff was warranted as they bridged the knowledge gap of HFR intervention readiness and could support findings suggesting that having boots on the ground is an essential and crucial element in HFR intervention implementation. Within these counties, two distinct groups of participants were recruited for data collection 
gure 1. Five-Phase Consensus Modeling Process to Develop The Policy, Systems, and Environmental Strategies

adiness Assessment and Decision Instrument (READI) for implementing healthy food retail project.

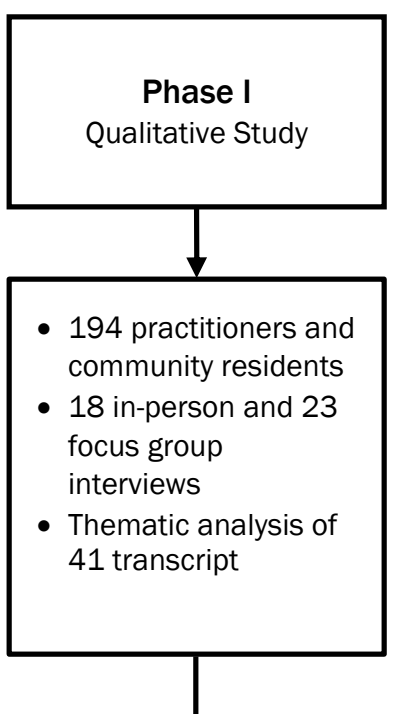

20 initial themes were developed from 1,091 open codes

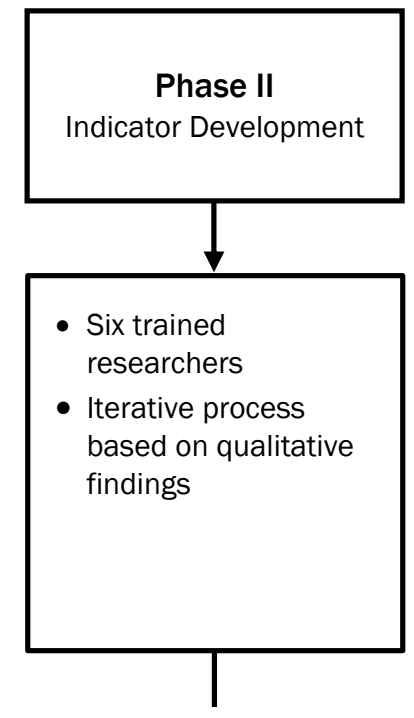

36 initial indicators representing six themes were developed
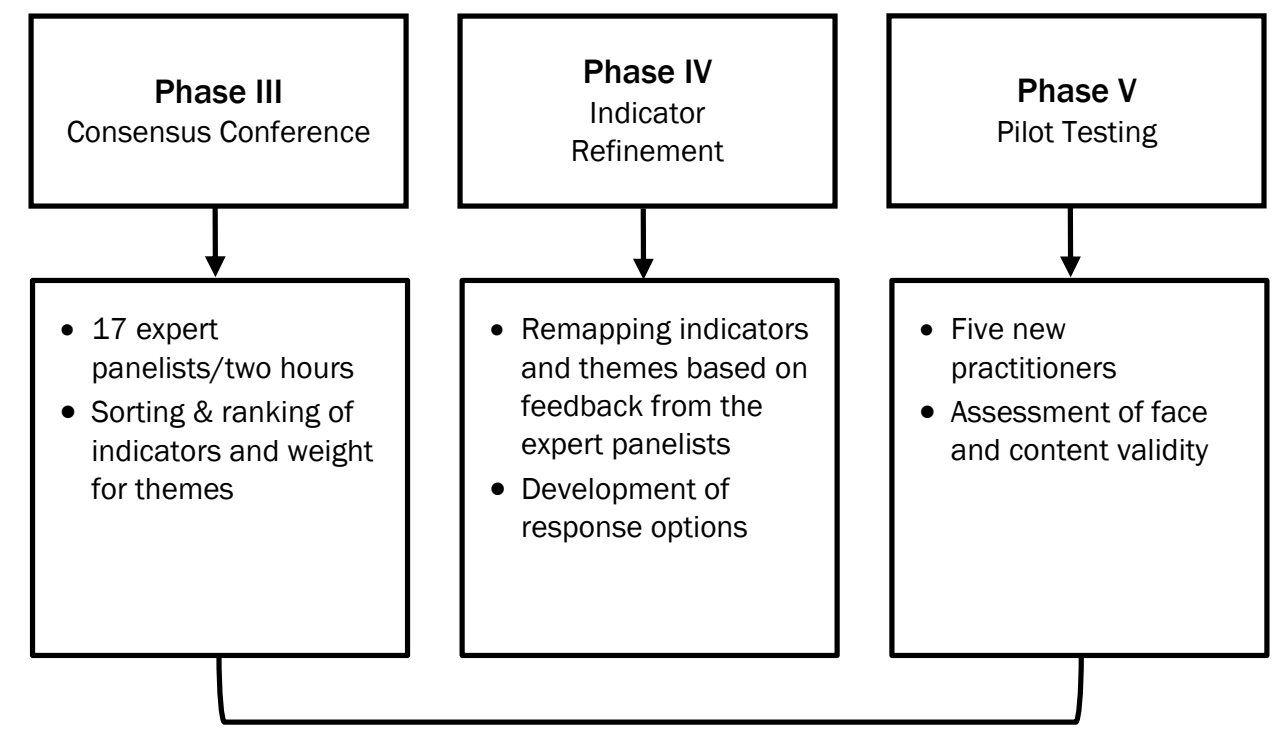
Narrowed to five themes and their associated 18 indicators

rst, public health and community nutrition practitioners from NAP-Ed or CHC were recruited by email. If interested, practitioners irticipated in one-on-one interviews. Second, community members ceiving or eligible to receive federal food assistance benefits and embers of CHC coalitions were recruited via flyers. Interested mmunity members called the study phone line to learn about the ady and sign up for a focus group. Informed consent was obtained om all participants. The institutional review board of Case Western eserve University approved the study.

ata Collection and Analysis

ne interview and focus group guides (Supplementary Materials 1 and 2, uploaded as separate files) were developed by the research team based on a review of the extant literature on conceptual models focused on factors associated with implementing nutrition-related PSE interventions (Blanck \& Kim, 2012; Frieden, 2010; Wandersmar et al., 2008). Interview and focus group questions were developed to identify participants' perceptions of factors that may influence the implementation of healthy eating PSEs, including community readiness, organizational readiness, practitioner capacity, the local burden of obesity, and sociopolitical context. The interview and focus group guides used, and their objectives, were the same for all practitioners and community members. Researchers, county- and state-level public health and community nutrition practitioners, and cooperative 
extension professionals reviewed and provided feedback on the interview and focus group guides as they were developed. Examples of healthy eating PSEs in retail food outlets were provided to develop a standard definition among participants during data collection. Between April and June 2015, semi-structured and open-ended in-person interviews and focus groups were conducted. These took place in various locations, such as community centers and practitioner offices. Interviews and focus groups were led by two trained researchers and lasted one- to two hours. They were digitally recorded and transcribed verbatim by a third-party transcriptionist. All transcripts $(N=41)$ were checked for accuracy against original recordings by the research team members.

A grounded theory approach (Charmaz, 2002) was used to analyze the transcripts in Atlas.ti (version 7) (Scientific Software Development GmbH, 2015). Details regarding the coding structure hierarchy are described elsewhere (Cascio et al., 2019). Briefly, first, trained researchers developed "open codes" grounded in participants' real words and captured the emerging concepts through a lineby-line reading of the transcripts. All open codes were co-coded with an associated PSE code to facilitate data analysis relevant to HFR projects. Second, each open code was assigned to a subtheme and then to a higher-level theme code to develop the coding structure. These processes guided the development of a codebook with themes, subthemes, and definitions used by the team to analyze the remaining transcripts. Third, the most salient themes and subthemes were prioritized. The selected subthemes were then operationalized into measurable indicators along with operational definitions of each theme.

The sample consisted of 194 participants, with 18 taking part in an interview and 176 participants taking part in one of 23 focus groups. Of these 194 participants, 20 were practitioners, 11 were $\mathrm{CHC}$ practitioners, and nine were SNAP-Ed practitioners. The remaining participants $(n=174)$ were community members who were current recipients or were eligible to receive SNAP $(n=127)$ or were CHC coalition members $(n=47)$. Most focus group participants were female $(69 \%)$ and self-reported current receipt of federal assistance benefits such as SNAP (65\%). More than half identified as white $(60 \%)$, and the remaining focus group participants identified as African American (40\%). Demographic characteristics were not recorded for practitioners who participated in the in-person interview because of the small sample size and the risk of losing confidentiality.

\section{Consensus Conference}

An expert panel reviewed indicators derived from the qualitative data analysis during a face-to-face consensus conference. A consensus conference's primary goal is to determine the extent to which a select sample of stakeholders agree with potential causes and solutions to targeted issues through iterative discussion and reflection (Lee et al., 2017). To improve validity, consensus conference participants consist of experts in the field who have credibility with the target audience (Murphy et al., 1998). According to the literature, the optimal number of expert panelists in a consensus conference is at least six participants to be more reliable (Kea \& Sun, 2015). Our consensus conference consisted of a panel of 17 experts, which is well above the recommended sample size. The expert panelists were recruited based on their expertise in HFR intervention design and management, experience in community nutrition practice, and/or experience working with low-income populations. The goal of this panel was to generate ideas, discuss disputed options, and ultimately synthesize stakeholder opinions to understand the value of the indicators for HFR implementation. The expert panelists $(N=17)$ participated in three activities to prioritize the themes and indicators based on their perceived relevance and importance for successful HFR implementation. First, two or three panelists worked together to sort indicators into thematic piles. Second, the same groups selected the top three indicators within each theme pile based on their perceived importance to successfully implementing HFR projects. These rankings were used to develop a standardized indicator weight ranging from not at all (coded as 0) to extremely (coded as 5). Lastly, panelists individually assigned a weight to each theme by manually distributing 25 tokens, with more tokens indicating greater perceived theme relevance for HFR implementation. These 
theme weights were used to develop standardized theme weights (range: 0-1). After the consensus conference, the research team refined and/or merged themes and indicators representing similar concepts. Indicators within each theme that accounted for $80 \%$ of the total indicator weight (range: 0-1) were selected for a final set of indicators to develop a parsimonious assessment tool (see Lee et al., 2017, for details).

Through an iterative process using a consensus conference with an expert panel, results were further refined. The themes presented came from the 1,091 codes produced through qualitative data analysis. These codes were then refined into five themes and 18 indicators through the consensus conference process. The panel of experts selected the final five themes as being the most critical factors related to implementing HFR projects. These final themes included corner store awareness and perception; organizational and practitioner capacity; logistical factors; community attitudes and perceptions; and networks and relationships. The corresponding indicators and standardized weights for both the theme and indicators are presented in Table 1. These standardized weights resulted from ranking exercises conducted with the expert panel and research team.

Table 1. Final Themes and Indicators for HFR Interventions Based on Indicator and Theme Ranking Exercises Conducted with the Expert Panel and Refinement by the Research Team

\begin{tabular}{|c|c|c|c|c|}
\hline Theme & Theme description & $\begin{array}{l}\text { Standardized } \\
\text { Theme } \\
\text { Weight }\end{array}$ & Indicator & $\begin{array}{l}\text { Standardized } \\
\text { Indicator } \\
\text { Weight }\end{array}$ \\
\hline \multirow[t]{3}{*}{$\begin{array}{l}\text { Corner store } \\
\text { awareness and } \\
\text { perception }\end{array}$} & \multirow[t]{3}{*}{$\begin{array}{l}\text { Perceptions of profitability } \\
\text { and motivators to use } \\
\text { healthy food retail PSE } \\
\text { projects. }\end{array}$} & \multirow[t]{3}{*}{0.24} & $\begin{array}{l}\text { To what extent do the owners of corner stores, } \\
\text { convenience stores, or gas stations in your service } \\
\text { area have positive perceptions about increasing } \\
\text { healthy food options for sale in their stores? }\end{array}$ & 0.41 \\
\hline & & & $\begin{array}{l}\text { To what extent do the owners of corner stores, } \\
\text { convenience stores, or gas stations in your service } \\
\text { area perceive that healthy food retail programs } \\
\text { would increase their profits? }\end{array}$ & 0.33 \\
\hline & & & $\begin{array}{l}\text { To what extent are the owners of corner stores, } \\
\text { convenience stores, or gas stations in your service } \\
\text { area interested in implementing healthy food retail } \\
\text { PSE projects? }\end{array}$ & 0.26 \\
\hline \multirow[t]{4}{*}{$\begin{array}{l}\text { Organizational } \\
\text { and } \\
\text { practitioner } \\
\text { capacity }\end{array}$} & \multirow{4}{*}{$\begin{array}{l}\text { Capacity to maintain } \\
\text { budgets, staffing, and } \\
\text { resources to implement } \\
\text { and evaluate healthy food } \\
\text { retail PSE projects in } \\
\text { corner stores. }\end{array}$} & \multirow[t]{4}{*}{0.22} & $\begin{array}{l}\text { To what extent does your current organizational or } \\
\text { program budget have funds to support } \\
\text { implementation of healthy food retail PSE projects in } \\
\text { your service area? }\end{array}$ & 0.43 \\
\hline & & & $\begin{array}{l}\text { To what extent does your organization have staff who } \\
\text { are available to support implementation of healthy } \\
\text { food retail PSE projects in your service area? }\end{array}$ & 0.25 \\
\hline & & & $\begin{array}{l}\text { To what extent does your current work plan include } \\
\text { healthy food retail PSE projects? }\end{array}$ & 0.20 \\
\hline & & & $\begin{array}{l}\text { In the past year, to what extent did you assess the } \\
\text { number of corner stores, convenience stores, or gas } \\
\text { stations in your service area that have healthy food } \\
\text { choices available for purchase? }\end{array}$ & 0.13 \\
\hline $\begin{array}{l}\text { Logistical } \\
\text { factors }\end{array}$ & $\begin{array}{l}\text { Transportation, location, } \\
\text { and distribution and } \\
\text { sourcing systems that are } \\
\text { associated with } \\
\text { implementing healthy food }\end{array}$ & 0.19 & $\begin{array}{l}\text { To what extent is it easier for people receiving SNAP } \\
\text { benefits and other low-income populations in your } \\
\text { service area to access a corner store, a convenience } \\
\text { store, or gas station by public transportation or } \\
\text { walking compared to a grocery store? }\end{array}$ & 0.39 \\
\hline
\end{tabular}


retail PSE projects in corner stores.
To what extent are there corner stores, convenience

0.32

stores, or gas stations available in low-income neighborhoods in your service area?

To what extent is there a distribution and sourcing system in your service area to provide corner stores, convenience stores, or gas stations with access to produce and other healthy food items?

\begin{tabular}{|c|c|}
\hline $\begin{array}{l}\text { Community } \\
\text { attitudes and } \\
\text { perceptions }\end{array}$ & $\begin{array}{l}\text { The perceptions, aware- } \\
\text { ness, and motivations in a } \\
\text { community that affect } \\
\text { implementation of healthy } \\
\text { food retail projects in } \\
\text { corner stores. }\end{array}$ \\
\hline
\end{tabular}

To what extent do people receiving SNAP benefits

and other low-income populations in your service area have positive views of corner stores, convenience stores, or gas stations as places to buy fresh produce or other healthy food options?

To what extent do people receiving SNAP benefits and other low-income populations in your service area have positive perceptions about the quality of produce or other healthy food options available in corner stores, convenience stores, or gas stations?

To what extent are people receiving SNAP benefits and other low-income populations in your service area aware of healthy food retail projects taking place in your service area?

To what extent are people receiving SNAP benefits and other low-income populations in your service area willing to use corner stores, convenience stores, or gas stations to purchase fresh produce and other healthy food options?

\begin{tabular}{|c|c|}
\hline $\begin{array}{l}\text { Networks and } \\
\text { relationships }\end{array}$ & $\begin{array}{l}\text { Social capital from which } \\
\text { practitioners and com- } \\
\text { munity members can draw } \\
\text { upon to help implement } \\
\text { and support healthy food } \\
\text { retail PSE projects }\end{array}$ \\
\hline
\end{tabular}

0.17 To what extent are you involved with or connected to other practitioners who are currently working on, or have worked on, healthy food retail PSE projects?

To what extent are there community engagement programs available in your service area to mobilize low-income residents to become engaged in efforts to increase the amount of healthy foods for sale at corner stores, convenience stores, or gas stations?

To what extent have you been successful at partnering with a food store owner either by yourself or through a partnership to increase their supply of healthy foods?

In the past year, to what extent did you collaborate with food retailers to develop marketing tools (e.g., signs, point-of-purchase labels) to raise awareness about healthy food choices available in the stores?
0.41

0.37

0.30

0.41

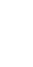

27

\section{Results}

\section{Corner Store Awareness and Perception}

The corner store awareness and perception theme received the highest standardized weight (0.24). This theme refers to perceptions of profitability and motivators among corner store staff to conduct HFR projects. Within this theme are three indicators arranged from highest to lowest weights received. The first indicator refers to store owners' perceptions of increasing healthy food within their stores $($ weight $=0.41)$. Overall, participants dis- 
cussed concerns about store owners' ability to maintain healthy food options. One participant said, "One of the barriers that we've heard ... is that ... store owners were worried that the produce would go bad or ... wouldn't be used" (Interview, urban).

Additionally, there is a belief that corner store owners lack time to engage in new initiatives like HFR that require an effort to rework their business model. An interviewee from a rural community expressed that corner store owners often work "double- or triple-duty" because they "have other full-time jobs and do other things." Store owners' lack of time created challenges for HFR implementation. The second indicator is the extent store owners perceive that HFR programs would increase profits (weight $=0.33$ ). Participants often discussed how store owners were "hesitant about bringing produce in because ... they [weren't] sure it would sell" (Interview, urban).

The final indicator refers to the extent to which store owners are motivated to act on their interests related to implementing HFR projects (weight=0.26). While store owners may be interested in "entertaining" the idea of HFR projects, participants suggested store owners may not have a strong motivation to act on these interests. Further, there were other store-level factors identified as key to motivating engagement in HFR projects. One participant stated store owners might be inspired by "chain-wide implementation" of HFR versus a "store-by-store" approach,

[Store owners have] been pretty adamant that they don't wanna do a store-by-store implementation type process ... if they're gonna do anything [in] altering the infrastructure of their store, they wanna do it ... [chain]-wide.

(Interview, urban)

\section{Organizational and Practitioner Capacity}

The theme of organizational and practitioner capacity received the second highest standardized theme weight $(0.22)$. This theme focused on organizations' and practitioners' capacity to maintain funding, staffing, and resources to implement and evaluate corner store HFR projects. Of the four indicators within this theme, the first indicator is the availability of funds within organizations to support the implementation of HFR interventions (weight $=0.43$ ). There was agreement that HFR projects required financial capital to initiate. An urban community member shared that HFR projects that were "taking off" had "additional funding and staff." Another participant discussed the use of grant funds to expand HFR projects,

We started this [corner store] project here in 2012 with one store in the [neighborhood] . . . expanded to two more stores in 2013 and we are up to 11 stores since and we are expanding with another grant that we applied for ... our goal is to help them and to do 50 stores by the end of 2017. (Interview, urban)

The second indicator is the extent to which organizations have staff available to support HFR implementation (weight $=0.25$ ). In general, participants discussed this in terms of limited staff time available to provide technical assistance to stores. One participant stated,

I think ... it's important to combine as much technical assistance as possible and ... have that relationship with that store owner. (Interview, urban)

Another participant stated,

We have the curriculum, we have the information, it's all research ... and evidence-based, and it's not biased. We have all that. We have the expertise of how to make it work ... but I guess the real problem is the time. (Interview, urban)

The third indicator is the extent to which organizations' current work plans include HFR projects (weight $=0.20$ ). A challenge identified was the balance between HFR and other nutritionrelated PSE work. As a focus group participant from an urban community stated, "We have a lot going on" as they described the challenges related to concurrently supporting HFR projects and implementing other nutrition programs as well as fostering broader policy change "to make healthy 
foods more available and affordable and accessible in our communities." Participants also reported different phases of activity related to HFR projects. An early-stage activity may focus on ensuring a store is approved to accept food assistance benefits:

If the stores aren't SNAP and WIC accepted ... then we're gonna work to try to get them on board and get them the equipment that they need to become SNAP and WIC accepted. (Focus group, rural)

The final indicator refers to the extent to which organizations assessed the availability of healthy foods for purchase in corner stores within the past year (weight $=0.13$ ). Most participants discussed evaluating the availability of healthy foods at the community level via "health impact assessments," a survey tool to help communities, decision-makers, and practitioners make choices to improve public health through community design, or, as one participant stated,

(We collected surveys) where we looked at the whole county related to ... income levels, and looking at where the ... grocery stores were located. (Interview, urban)

The same participant also discussed collecting data via community surveys,

We looked at food access there [name of community] ... and we did a community survey ... and it showed that people [in] the [neighborhood] of [city] [were in] great need for ... food access. (Interview, urban)

\section{Logistical Factors}

The theme of logistical factors received the third highest standardized (weight $=0.19$ ). This theme refers to transportation, location, distribution, and sourcing systems associated with implementing corner store HFR projects. Within this theme were three indicators. The first indicator refers to the extent to which it is easier to access a corner store by public transportation or walking versus a supermarket (weight $=0.39$ ). Overall, participants per- ceived it is easier for people receiving SNAP benefits and other low-income populations without a car to access a corner store than a supermarket. One participant stated that lack of transportation made it difficult to get to the supermarket, so people with SNAP go "to the ... gas station or something where non-healthier stuff is" (Focus group, rural).

The second indicator refers to the lack of balance regarding access to supermarkets versus corner stores (weight $=0.32$ ). One participant stated,

There's no grocery stores, so a lot of people rely on those gas stations ... I have a gas station near my house, and I'm never going to find skim milk in that place. (Focus group, rural)

Another focus group participant from an urban community discussed the overabundance of convenience stores by stating, "There [are] a lot of convenience stores. No major [supermarkets]."

The final indicator refers to the existing distribution and sourcing systems that provide corner stores with access to healthy food items (weight= $0.30)$.

I think the biggest barrier continues to be there is not a good system of procurement for any type of food, let alone healthy food for corner stores. It is not unusual for the corner stores to ... go to Costco or Sam's Club and Aldi and purchase products and bring it back and mark it up because they are going to go through 10 gallons of milk in a week and ... the distributors ... do 100 gallons or whatever it might be. (Focus group, urban)

\section{Community Attitudes and Perceptions}

The theme of community attitudes and perceptions received the fourth highest rating from the expert panel (0.18). This theme refers to the perceptions, awareness, and motivations in a community that affect implementation of HFR corner store interventions. Within this theme were four indicators. The indicator with the highest weight (0.41) refers to the extent to which people receiving SNAP 
benefits and other low-income individuals have favorable views of corner stores as places to buy healthy foods. Overall, the consensus was that these outlets are not the right place to purchase healthy foods. Additionally, participants discussed the challenge of changing perceptions of these stores as healthy food outlets. As one participant stated,

Changing that perception ... I think it's going to be a challenge ... but I think ... we can assist with marketing $\ldots$ and holding different community events for people. Getting the residents used to ... being in the store and coming to the store [to buy healthy food], and getting to know the owner themselves [and building] rapport with the ... store owner ... but then also, the store owner seeing that people want to see [their] store and showing the store owner that [HFR] is not going to go to waste, and, educating him ... more about food handling, and proper ways to store food [to help change perception]. (Interview, urban)

The second indicator is the extent to which people receiving SNAP benefits and other lowincome individuals have positive perceptions of the quality of healthy foods in corner stores (weight= 0.27). Like the previous indicator, overall perceptions regarding quality were generally negative. As one participant stated,

Most ... corner stores, if you try to get healthier food ... fruits and all that ... they're not gonna take care of it better than if you had a farmer market ... because ... most of [their] stuff [are] rotten, no good ... mushy cause they don't care. [Store owners] just don't. I don't see it'd be the best place to put healthy foods because it ain't gonna be worth it when you pay your money for it. You're not gonna get top quality. (Focus group, urban)

The third indicator is the extent people receiving SNAP benefits and other low-income populations are aware of HFR projects (weight= 0.18). Participants generally agreed that organization-level individuals were aware, but community members were not. As one participant said,

I think the stakeholders in the communities where it is active most [are] aware, but I think the community as a whole ... if you don't see fresh foods here or stores in your neighborhood, you probably aren't aware of it. (Focus group, urban)

Overall, most participants agreed that community members needed to become aware of HFR projects.

The final indicator relates to the extent to which people receiving SNAP benefits and other low-income populations are willing to use corner stores to purchase healthy food (weight $=0.14$ ). Overall, perceptions of buying healthy food from these food outlets were negative. One participant stated,

I am not goin' to no gas station buyin' no fruit, I don't care how pretty it looks, it's goin' to be too much ... the idea of sending my son down to the gas station for a basket of apples, nah, it's not for that. (Focus group, urban)

\section{Networks and Relationships}

The final theme with the lowest standardized rating $(0.17)$ is networks and relationships, which refers to relationships and support systems that help practitioners implement HFR projects in corner stores. Within this theme were four indicators. The first refers to the extent to which practitioners are involved with or connected to other practitioners currently working on or have worked on HFR projects (weight $=0.37$ ). One participant stated,

[We] connected with other [public health] coordinators around the state through the online list by the local organization ... [to learn what] they doing and what works for them ... what doesn't work. (Interview, urban)

Additionally, participants discussed the importance of connecting with community organizations or essential players in the food systems field to be successful in implementing an HFR project, 
You have to build those relationships with stores ... and [with the] community ... from big grocers all the way down to the corner stores ... building relationships with the farmers ... and distributors that you can ... hopefully get healthy food into those retail outlets. (Focus group, urban)

The second indicator refers to the extent to which community engagement programs are available to mobilize low-income residents to engage in efforts to increase healthy foods in corner stores (weight $=0.26$ ). Most participants discussed engagement programs by discussing relationships with community members. One participant discussed multiple community organization partnerships in the hopes that it would increase community awareness of HFR efforts:

It's getting ... more people at the table cause we have a monthly [coalition] meeting that encompasses people from like [university], including [name of county early childcare programs] and [name of funders] and ... the [name of hospital system] ... and [name of coalition members] ... I mean, there's a lot of different organizations. The county commissioners know about it, the city council ... knows about it ... family services know about it, but how do all the people in the community know about it? (Interview, urban)

The third indicator within the theme of networks and relationships refers to the extent practitioners were successful in partnering with store owners to increase HFR options (weight $=0.20$ ). Most participants stated the positive aspects of partnering with store owners as demonstrating both the success in building relationships with store owners and owners' willingness to work on HFR. One participant stated that when they have questions about selling healthy foods within smaller food outlets, they turn to store owners. Another participant discussed how their success extended beyond increasing access to healthy foods. Some were able to use the store environment for community events as well,
There's been quite a few ... active store[s] [and] owners that ...helped the community ... with assistance of the development corporation ...they've ... held different community events in their stores. (Interview, urban)

The final indicator within this theme refers to the extent practitioners collaborate with food retailers to develop marketing tools to raise awareness about healthy food within stores (weight= 0.17). Overall, participants discussed their current efforts to market not only the healthy food within corner stores but also their efforts to market these food outlets as Healthy Food Retailers:

We can $\ldots$ assist with marketing $\ldots$ and holding different community events for people, the residents who get used to seeing, being in the store, and coming to the store, and getting to know the owner themselves. (Interview, urban)

The same participant continued to discuss how they hope to help with the marketing of healthy foods,

We're hoping to put better signage around healthy foods in the windows and ... around the healthy food areas. [Help] to make the, um ... displays greater [for healthy foods]. (Interview, urban)

\section{Discussion}

This study reveals five themes considered the most critical factors related to implementing HFR projects. These themes were: corner store awareness and perception; organizational and practitioner capacity; community attitudes and perceptions; logistical factors; and networks and relationships. Additionally, 18 indicators were identified within the five themes that illustrate influential factors related to the implementation of HFR projects. The highest-rated indicator(s) for each domain included organizational budget for HFR projects and store owners' perceptions of increasing healthy food options for sale in their stores; availability of staff to implement HFR projects; community members' perceptions of corner stores as HFR settings; community members' ability to travel to a 
corner store compared to a supermarket; and connections to other practitioners who are currently working on or have previously worked on HFR projects.

PSE strategies for HFR interventions have become increasingly recognized as a potential solution to reduce overweight and obesity trends (Adam \& Jensen, 2016; Gittelsohn et al., 2012). In practice, HFR interventions are more likely to be successful when there is funding to provide adequate technical assistance to retail food outlets, in addition to funding tailored intervention strategies (Caspi et al., 2016; Greco et al., 2020; Laska et al., 2009; Rushakoff et al., 2017). With this, there needs to be buy-in from retail food outlets and community members (Haynes-Maslow et al., n.d.; Houghtaling et al., 2019; Martinez, Rodriguez et al., 2018). Study findings demonstrate that organizations are receiving funding for $\mathrm{HFR}$, demonstrating their value to practitioners, organizations, and the broader community. However, the findings highlight that funding should be used to develop and implement HFR interventions and build store owners' relationships. By building relationships with owners, program staff can identify intervention methods to stock and/or promote healthy foods that align with an owner's goals, business model, and resources (Houghtaling et al., 2019).

Like previous research, another significant finding from this research is community members' perceptions (Blitstein et al., 2012). Community support is essential to HFR interventions' success, given that retail food outlets are primarily driven by consumer demand and profits (Bodor et al., 2010). If healthy foods are not selling, store owners may choose to replace those foods with unhealthy products. Participants in this study perceived healthy foods in corner stores to be of low quality. This perception is consistent with previous research examining the quality of healthy foods in small stores and nontraditional retail food outlets, which found these foods low quality than supermarkets (Block \& Kouba, 2006; Cummins et al., 2008). The low quality of healthy foods in small stores and nontraditional retail food outlets demonstrates the need to train corner store owners to select, stock, and maintain healthy foods (Karpyn et al., 2018). After this skill is attained and mastered, PSE and in-store promotional strategies, such as choice architecture strategies (Bucher et al., 2016; Thorndike \& Sunstein, 2017), can occur to promote these foods.

Utilizing corner stores as settings for HFR is essential, given that a significant barrier to shopping at a supermarket for community members is a lack of transportation. Lack of transportation has been cited as a barrier in previous community food environment research (Walker et al., 2010b). Utilizing existing retail food outlets versus opening a supermarket may be a more realistic and costeffective approach to improving a community's food environment (Cameron et al., 2016). Previous research has demonstrated that opening a supermarket in a food desert did not improve healthy food purchasing, potentially showing the importance of PSE and in-store strategies within existing retail food outlet spaces to encourage healthy food purchasing (Cummins et al., 2014).

Other significant findings from this study relate to organizational capacity to implement HFR interventions. Like the need for HFR funding, participants stated the need to focus on HFR and the need for connections to other practitioners who are currently working on or have previously worked on HFR projects. Making such connections may help to build strategic partnerships with academic and/or community partners who are savvy in the topic of HFR to support development and implementation (Holden et al., 2016). Strategic partnerships can help identify areas of need and provide implementation support. Still, such partnerships can also mean tapping into others' expertise and gaining insight into their lessons learned to develop evidence-based HFR interventions successfully. As found in previous research, the provision of resources and skill development training is needed to identify, build, maintain and strengthen strategic partnerships (Shah et al., 2019).

Implementation of HFR interventions involves a balancing act of improving the overall food environment (e.g., the increased supply of healthy foods) within retail food outlets as well as creating consumer demand for healthy foods (Karpyn \& Hannah, 2013; Pitt et al., 2017). Recent research has identified multiple points of intervention that affect the environment within retail food outlets, 
ranging from the managerial-level (e.g., lack of knowledge among store owners to source and maintain healthy foods) to the infrastructure-level (e.g., limited in-store space to stock healthy foods) (Houghtaling et al., 2019; Karpyn \& Hannah, 2013). Parallel efforts should occur to encourage healthy food purchasing among consumers to increase demand. Actions could include improving customer service to build stronger relationships between retail food outlet staff and consumers (Sanchez-Flack et al., 2016; Webber et al., 2010), marketing mix strategies (e.g., strategic placement) to nudge consumers to purchase healthy foods (Castro et al., 2018), and assisting retail food outlets with becoming certified nutrition assistance program vendors (DeWeese et al., 2016).

Findings from the present study highlight the need to provide technical assistance to practitioners and store owners to implement HFR interventions. Practitioners reported barriers to building relationships with store owners and building relationships with other practitioners with HFR intervention experience. Providing practitioners with the skills to build relationships with store owners means assisting them first in connecting with other practitioners. Practitioners with HFR intervention experience have critical insight into how to reach and engage store owners. Potential strategies to connect practitioners may be through networking events or roundtable discussions at conferences or organizing a national meeting where practitioners awarded an HFR grant can meet one another and discuss their work.

Efforts should also be conducted to get successful support and buy-in from store owners. Gaining their support may assist in the relationship-building process. Referring store owners to publicly available tools and resources about HFR may help them understand these programs and what it means for their business. It may also encourage highly motivated owners to independently implement suggested strategies to promote healthy foods within their stores. Supporting store owners in HFR through publicly available resources, providing technical assistance, and strategic partnerships can lead to changes within the consumer food environment, changing the community's perspective towards corner stores, convenience stores, gas stations, and the like HFR outlets.

There were limitations to the present study. Participants represented different geographic areas of Ohio, which may reduce generalizability to other regions of the U.S. The expert panel's views may not reflect the full range of perspectives and experiences, as we did not interview food store owners and managers, about HFR interventions, which would impact the weights assigned to indicators and themes. Additional research may replicate methods with different stakeholders, including food store owners and managers, to gain consensus on the theme and indicator weights. Our interview and focus group guides solely focused on fresh fruit and vegetables for HFR interventions and neglected to consider other viable, healthy food options such as no- or low-sodium canned or frozen fruit and vegetables, thereby potentially limiting our findings in terms of HFR interventions targeting other forms of healthy foods.

Furthermore, the psychometric properties of indicators were not assessed and may be a potential avenue of future research. Facilitators of and barriers to implementation of HFR from the perspectives of experienced stakeholders have been operationalized into measurable indicators, resulting in the creation of PSE READI (Readiness Assessment and Decision Instrument tool (Building Capacity for Obesity Prevention, 2016). The online tool for practitioners helps assess community readiness and capacity to implement HFRs suiting the local context.

\section{Conclusions}

Designing, deploying, and evaluating HFR interventions is complex, detailed work. It requires understanding needs, fostering relationships, and building trust among stakeholders ranging from store owners, residents, and distributors at the community level, to funders, local health departments, and universities at the institutional level. Conducting informed groundwork for the effective launch of HFR strategies may be a resourceintensive and nonlinear work process but is crucial to success. The themes and indicators presented in this research have been synthesized into the PSE READI tool. Unlike many currently available HFR toolkits that offer a generalized approach to HFR 
interventions, the PSE READI tool provides an opportunity to assess, tailor, and implement HFR plans for local contexts by considering the key themes and influential factors that emerged from our research.

\section{Acknowledgments}

The authors would like to thank the participants for their time and support.

\section{References}

Adam, A., \& Jensen, J. D. (2016). What is the effectiveness of obesity related interventions at retail grocery stores and supermarkets?-a systematic review. BMC Public Health, 16(1), 1247-1264.

https://doi.org/10.1186/s12889-016-3985-x

Ayala, G. X., Baquero, B., Laraia, B. A., Ji, M., \& Linnan, L. (2013). Efficacy of a store-based environmental change intervention compared with a delayed treatment control condition on store customers' intake of fruits and vegetables. Public Health Nutrition, 16(11), 1953-1960. https://doi.org/10.1017/S1368980013000955

Blanck, H. M., \& Kim, S. A. (2012). Creating supportive nutrition environments for population health impact and health equity. American Journal of Preventive Medicine, 43(3), S85-S90. https://doi.org/10.1016/j.amepre.2012.06.005

Blitstein, J. L., Snider, J., \& Evans, W. D. (2012). Perceptions of the food shopping environment are associated with greater consumption of fruits and vegetables. Public Health Nutrition, 15(6), 1124-1129. https://doi.org/10.1017/S1368980012000523

Block, D., \& Kouba, J. (2006). A comparison of the availability and affordability of a market basket in two communities in the Chicago area. Public Health Nutrition, 977), 837-845. https://doi.org/https://doi.org/10.1017/phn2005924

Bodor, J. N., Ulmer, V. M., Futrell Dunaway, L., Farley, T. A., \& Rose, D. (2010). The rationale behind small food store interventions in low-income urban neighborhoods: Insights from New Orleans. Journal of Nutrition, 140(6), 11851188. https://doi.org/10.3945/jn.109.113266

Bucher, T., Collins, C., Rollo, M. E., Mccaffrey, T. A., De Vlieger, N., Van Der Bend, D., ... Perez-Cueto, F. J. A. (2016). Nudging consumers towards healthier choices: a systematic review of positional influences on food choice. British Journal of Nutrition, 115, 2252-2263. https://doi.org/10.1017/S0007114516001653

Building Capacity for Obesity Prevention. (2016). Tools for practitioners. Retrieved July 3, 2019, from https://psereadi.org/ Cameron, A. J., Charlton, E., Ngan, W. W., \& Sacks, G. (2016). A systematic review of the effectiveness of supermarketbased interventions involving product, promotion, or place on the healthiness of consumer purchases. Current Nutrition Reports, 5(3), 129-138. https://doi.org/10.1007/s13668-016-0172-8

Cascio, M. A., Lee, E., Vaudrin, N., \& Freedman, D. A. (2019). A team-based approach to open coding: Considerations for creating intercoder consensus. Field Methods, 31(2), 116-130. https://doi.org/10.1177/1525822X19838237

Caspi, C. E., Pelletier, J. E., Harnack, L., Erickson, D. J., \& Laska, M. N. (2016). Differences in healthy food supply and stocking practices between small grocery stores, gas-marts, pharmacies and dollar stores. Public Health Nutrition, 19(03). https://doi.org/10.1017/S1368980015002724

Castro, I. A., Majmundar, A., Williams, C. B., \& Baquero, B. (2018). Customer purchase intentions and choice in food retail environments: A scoping review. International Journal of Environmental Research and Public Health, 15, 2493-2502. https://doi.org/10.3390/ijerph15112493

Centers for Disease Prevention and Control. (2011). State Initiatives Supporting Healthier Food Retail: An overview of the national landscaper. Retrieved from http://apps.ams.usda.gov/

Charmaz, K. (2002). Grounded theory: methodology and theory construction. In N. J. Smelser \& P. B. Baltes (Eds.), International Encyclopedia of the Social and Behavioral Sciences (1st ed., pp. 6396-6399.). Pergamon.

Cummins, S., Flint, E., \& Matthews, S. (2014). New neighborhood grocery store increased awareness of food access but did not alter dietary habits or obesity. Health Affairs, 33(2), 2830291. https://doi.org/10.1377/hlthaff.2013.0512

Cummins, S., Smith, D. M., Taylor, M., Dawson, J., Marshall, D., Sparks, L., \& Anderson, A. S. (2008). Variations in fresh fruit and vegetable quality by store type, urban-rural setting and neighbourhood deprivation in Scotland. Public Health Nutrition, 12(11), 2044-2050. https://doi.org/10.1017/S1368980009004984 
Dannefer, R., Williams, D. A., Baronberg, S., \& Silver, L. (2012). Healthy bodegas: increasing and promoting healthy foods at corner stores in New York City. American Journal of Public Health, 102(10), e27-e31. https://doi.org/10.2105/AJPH.2011.300615

DeWeese, R. S., Todd, M., Karpyn, A., Yedidia, M. J., Kennedy, M., Bruening, M., ... Ohri-Vachaspati, P. (2016). Healthy store programs and the Special Supplemental Nutrition Program for Women, Infants, and Children (WIC), but not the Supplemental Nutrition Assistance Program (SNAP), are associated with corner store healthfulness. Preventive Medicine Reports, 4, 256-261. https://doi.org/10.1016/j.pmedr.2016.06.018

Farley, S. M., Sacks, R., Dannefer, R., Johns, M., Leggat, M., Lim, S., .. Nonas, C. (2015). Evaluation of the New York City Green Carts program. AIMS Public Health, 2(4), 906-918. https://doi.org/10.3934/publichealth.2015.4.906

Farley, T. A., Rice, J., Bodor, J. N., Cohen, D. A., Bluthenthal, R. N., \& Rose, D. (2009). Measuring the food environment: Shelf space of fruits, vegetables, and snack foods in stores. Journal of Urban Health, 86(5), 672-682. https://doi.org/10.1007/s11524-009-9390-3

Frieden, T. R. (2010). A framework for public health action: the health impact pyramid. American Journal of Public Health, 100(4), 590-595. https://doi.org/10.2105/AJPH.2009.185652

Gittelsohn, J., Rowan, M., \& Gadhoke, P. (2012). Interventions in small food stores to change the food environment, improve diet, and reduce risk of chronic disease. Preventing Chronic Disease, 9, E59. https://doi.org/10.5888/pcd9.110015

Glanz, K., \& Yaroch, A. L. (2004). Strategies for increasing fruit and vegetable intake in grocery stores and communities: policy, pricing, and environmental change. Preventive Medicine, 39, 75-80. https://doi.org/10.1016/j.ypmed.2004.01.004

Glanz, K., Sallis, J. F., Saelens, B. E., \& Frank, L. D. (2005). Healthy nutrition environments: Concepts and measures. American Journal of Health Promotion, 19(5), 330-333. https://doi.org/10.4278/0890-1171-19.5.330

Greco, L., Kolodinsky, J., Sitaker, M., Chase, L., Conner, D., Estrin, H., Smith, D., \& Van Soelen Kim, J. (2020). Farm Fresh Food Boxes: Relationships in Value Chain Partnerships. Journal of Agriculture, Food Systems, and Community Development, 9(4), 113-129. https://doi.org/10.5304/jafscd.2020.094.012

Hartmann-Boyce, J., Bianchi, F., Piernas, C., Riches, S. P., Frie, K., Nourse, R., \& Jebb, S. A. (2018). Grocery store interventions to change food purchasing behaviors: a systematic review of randomized controlled trials. American Journal of Clinical Nutrition, 107(6), 1004-1016. https://doi.org/10.1093/ajcn/nqy045

Haynes-Maslow, L., Osborne, I., \& Pitts, S. B. J. (n.d.). Best Practices and Innovative Solutions to Overcome Barriers to Delivering Policy, Systems and Environmental Changes in Rural Communities. https://doi.org/10.3390/nu10081012

Holden, K., Akintobi, T., Hopkins, J., Belton, A., McGregor, B., Blanks, S., \& Wrenn, G. (2016). Community engaged leadership to advance health equity and build healthier communities. Social Sciences, 5(1), 2. https://doi.org/10.3390/socsci5010002

Houghtaling, B., Serrano, E. L., Kraak, V. I., Harden, S. M., Davis, G. C., \& Misyak, S. A. (2019). A systematic review of factors that influence food store owner and manager decision making and ability or willingness to use choice architecture and marketing mix strategies to encourage healthy consumer purchases in the United States, 20052017. International Journal of Behavioral Nutrition and Physical Activity, 16(1), 5. https://doi.org/10.1186/s12966-019-0767-8

Karpyn, A., DeWeese, R. S., Pelletier, J. E., Laska, M. N., Ohri-Vachaspati, P., Deahl-Greenlaw, A., ... Jilcott Pitts, S. B. (2018). Examining the feasibility of healthy minimum stocking standards for small food stores. Journal of the Academy of Nutrition and Dietetics, 118(9), 1655-1663. https://doi.org/10.1016/j.jand.2017.12.006

Karpyn, A., \& Hannah, B.-L. (2013). Rethinking research: Creating a practice-based agenda for sustainable small-scale healthy food retail. Journal of Agriculture, Food Systems, and Community Development, 3(4), 139-143. https://doi.org/https://doi.org/10.5304/jafscd.2013.034.015

Kea, B., \& Sun, B. C. A. (2015). Consensus development for healthcare professionals. Internal and Emergency Medicine, 10 , 373-383. https://doi.org/10.1007/s11739-014-1156-6 
Langellier, B. A., Garza, J. R., Prelip, M. L., Glik, D., Brookmeyer, R., \& Ortega, A. N. (2013). Corner store inventories, purchases, and strategies for intervention: A review of the literature. Californian Journal of Health Promotion, 11(3), 1-13. https://doi.org/10.32398/cjhp.v11i3.1537

Larson, N. I., Story, M. T., \& Nelson, M. C. (2009). Neighborhood environments. American Journal of Preventive Medicine, 36(1), 74-81.e10. https://doi.org/10.1016/j.amepre.2008.09.025

Laska, M. N., Borradaile, K. E., Tester, J., Foster, G. D., \& Gittelsohn, J. (2009). Healthy food availability in small urban food stores: a comparison of four U.S. cities. Public Health Nutrition, 13(7), 1031-1035. https://doi.org/10.1017/S1368980009992771

Lee, E., Dalton, J., Ngendahimana, D., Bebo, P., Davis, A., Remley, D., ... Freedman, D. A. (2017). Consensus modeling to develop the farmers' market readiness assessment and decision instrument. Translational Behavioral Medicine, 7(3), 506-516. https://doi.org/10.1007/s13142-017-0504-2

Lee, E., Smathers, C., Zubieta, A. C., Ginnetti, S., Shah, A., \& Freedman, D. A. (2019). Identifying indicators of readiness and capacity for implementing Farm-to-School interventions. Journal of School Health, 89(5), 373-381. https://doi.org/10.1111/josh.12747

Martinez, O., Rodriguez, N., Mercurio, A., Bragg, M., \& Elbel, B. (2018). Supermarket retailers' perspectives on healthy food retail strategies: in-depth interviews. BMC Public Health, 18(1), 1019. https://doi.org/10.1186/s12889-018-5917-4

Morland, K., Diez Roux, A. V., \& Wing, S. (2006). Supermarkets, other food stores, and obesity. American Journal of Preventive Medicine, 30(4), 333-339. https://doi.org/10.1016/j.amepre.2005.11.003

Murphy, Black, Lamping, McKee, Sanderson, Askham, \& Marteau. (1998). Consensus development methods, and their use in clinical guideline development. Health Technology Assessment, 2(3). https://doi.org/10.3310/hta2030

Parsons, A. A., Monteban, M., Lee, E., Bebo, P., Zubieta, A. C., Ginnetti, S., ... Freedman, D. (2019). Indicators of readiness and capacity for implementation of healthy eating strategies in child care settings serving low-income children. Journal of Nutrition Education and Behavior, 51(4), 465-477. https://doi.org/10.1016/i.jneb.2018.09.004

Pinard, C. A., Byker Shanks, C., Harden, S. M., \& Yaroch, A. L. (2016). An integrative literature review of small food store research across urban and rural communities in the U.S. Preventive Medicine Reports, 3, 324-332. https://doi.org/10.1016/j.pmedr.2016.03.008

Pitt, E., Gallegos, D., Comans, T., Cameron, C., \& Thornton, L. (2017). Exploring the influence of local food environments on food behaviours: a systematic review of qualitative literature. Public Health Nutrition, 20(13), 2393-2405. https://doi.org/10.1017/S1368980017001069

Rushakoff, J. A., Zoughbie, D. E., Bui, N., Devito, K., Makarechi, L., \& Kubo, H. (2017). Evaluation of Healthy2Go: A country store transformation project to improve the food environment and consumer choices in Appalachian Kentucky. Preventive Medicine Reports, 7, 187-192. https://doi.org/10.1016/j.pmedr.2017.06.009

Sanchez-Flack, J. C., Baquero, B., Linnan, L. A., Gittelsohn, J., Pickrel, J. L., \& Ayala, G. X. (2016). What influences Latino grocery shopping behavior? Perspectives on the small food store environment from managers and employees in San Diego, California. Ecology of Food and Nutrition, 55(2), 163-181.

https://doi.org/10.1080/03670244.2015.1112282

Scientific Software Development GmbH. (2015). Atlas.ti. Berlin, Germany: Scientific Software Development GmbH.

Shah, H. D., Adler, J., Ottoson, J., Webb, K., \& Gosliner, W. (2019). Leaders' experiences in planning, implementing, and evaluating complex public health nutrition interventions. Journal of Nutrition Education and Behavior, 51(5), 528538. https://doi.org/10.1016/J.JNEB.2019.02.005

Story, M., Kaphingst, K. M., Robinson-O’Brien, R., \& Glanz, K. (2008). Creating healthy food and eating environments: Policy and environmental approaches. Annual Review of Public Health, 29(1), 253-272. https://doi.org/10.1146/annurev.publhealth.29.020907.090926

Thorndike, A. N., \& Sunstein, C. R. (2017). Obesity prevention in the supermarket-choice architecture and the Supplemental Nutrition Assistance Program. American Journal of Public Health, 107(10), 1582-1583.

https://doi.org/10.2105/AJPH.2017.303991 
Treuhaft, S., \& Karpyn, A. (2015). The Food Gap: Who has access to healthy food and why it matters. Retrieved from http://thefoodtrust.org/uploads/media items/grocerygap.original.pdf

Walker, R. E., Keane, C. R., \& Burke, J. G. (2010a). Disparities and access to healthy food in the United States: A review of food deserts literature. Health and Place, 16(5), 876-884. https://doi.org/10.1016/j.healthplace.2010.04.013

Walker, R. E., Keane, C. R., \& Burke, J. G. (2010b). Disparities and access to healthy food in the United States: A review of food deserts literature. https://doi.org/10.1016/i.healthplace.2010.04.013

Wandersman, A., Duffy, J., Flaspohler, P., Noonan, R., Lubell, K., Stillman, L., ... Saul, J. (2008). Bridging the gap between prevention research and practice: the interactive systems framework for dissemination and implementation. American Journal of Community Psychology, 41(3-4), 171-181. https://doi.org/10.1007/s10464-008-9174-z

Webber, C. B., Sobal, J., \& Dollahite, J. S. (2010). Shopping for fruits and vegetables. Food and retail qualities of importance to low-income households at the grocery store. Appetite, 54(2), 297-303.

https://doi.org/10.1016/j.appet.2009.11.015 